\title{
Plugging slurry (backfill) and surface cavity closure technology
}

\author{
Al'bert Prokopov ${ }^{1}$, Marina Prokopova ${ }^{2}$, Sergei Stel'makh ${ }^{1}$, and Andrei Chernil'nik ${ }^{1^{*}}$ \\ ${ }^{1}$ Don State Technical University, Gagarin sq., 1, Rostov-on-Don, 344000, Russia \\ ${ }^{2}$ Rostov State Transport University, Narodnogo Opolcheniya sq., 2, Rostov-on-Don, 344038, Russia
}

\begin{abstract}
The purpose of the study is to study mining and environmental emergencies associated with the formation of sinkholes of the earth's surface over mining workings after the mass closure of coal mines and to develop a new method for eliminating the sinkhole. The study used a method of physical modeling, which investigated the influence of humidity on the deformation properties of burnt rocks used as a filler in the manufacture of plugging and filling suspensions, while establishing the dependence of the relative deformation of dump rocks on the load at their natural humidity and water saturation. The main results of the research are: a new method for eliminating dips in the earth's surface over the inclined opening workings of the liquidated coal mines of the Eastern Donbass; formulations of plugging and filling suspensions used for layer-by-layer filling of sinkholes and providing non-shrink laying.
\end{abstract}

\section{Introduction}

Large-scale closure of coal mines in mining areas frequently causes mining-related environmental incidents attributable to many factors, including supra-opening surface cavities [1].

Analysis of the mine openings closed in Russia shows that most environmental incidents related to surface cavities are predetermined by critical ground pressure, aging-caused reduction in the supporting capacity of the supports, and the loss of stability in roof scaffolds, stoppings, and brows. All these factors may occur separately or in combinations, but they are interrelated and interconditioned anyway. In this case, all the interconditioned elements form a geotechnical system that determines the stability of the eliminated mine opening as well as the efficiency of the chosen closure method, see Figure 1.

*Corresponding author: chernila_a@mail.ru 


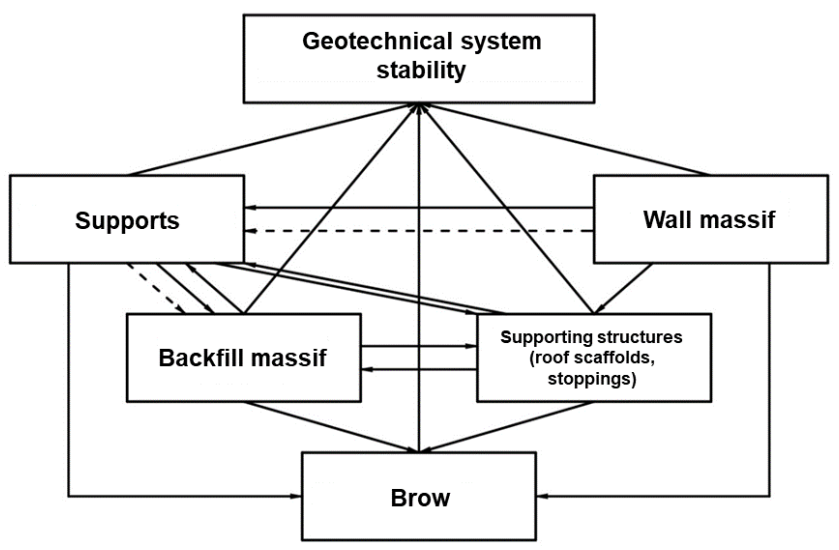

Fig. 1. Geotechnical system. Closed mine opening: solid line - direct interactions; dotted line indirect interactions.

The geotechnical safety of the Earth's surface at coal mine opening closure and backfilling sites is an issue covered by Yu.N. Gavrilenko, S.S. Grebenkin, V.N. Yermakov, P.N. Dolzhikov [1,2], M.A. Iofis, Ye.L. Zvyagilsky, N.M. Kachurin [3, 4], A.E. Kipko, O.I. Kosov, Yu.F. Krenida, A.N. Medyantsev, M.D. Molev [5, 6], A.V. Mokhov [7, 8], Pleshko M.S. [9, 10], A.V. Uglyanitsa, A.N. Feofanov, A.A. Shubin, I.F. Yarembash, N.V. Hamidullina $[1,11]$ et al. Karstification and emergence of surface cavities above potash mines were studied by A.A. Baryakh [12]. International researchers have studied [13] the safety of operating building and structures in situations where the emergence of surface cavities is likely.

In this case, the geotechnical system of a closed mine opening shall mean the totality of its elements: the wall massif, the supports, the backfill massif, the mine supporting structures, and the brow, which interact and affect each other in space and time.

The uncertain long-term stability of closed mine openings shall mean the equilibrium state of all geotechnical-system elements. It is important to preserve such equilibrium even if hydrogeological or seismic conditions alter.

Flooding of closed coal mines in Eastern Donbass cause large-scale surficial movements. Mining allotments of OAO Rostovugol's closed coal mines contain 449 brows; the emergence of surface cavities is intensifying. Immediate closure of such cavities may have unfavorable side effects, since such cavities are filled with burnt rock without identifying the causes of cavitation. This causes cavities to re-emerge, especially when openings are flooded [14-17]. This is why substantiating the parameters of the cavity closure method is a relevant scientific problem.

\section{Methods}

Experimental studies have been carried out [1] to develop a reliable, efficient, and easily applicable way to close cavities by layered backfilling with burnt rock and plugging slurry; the studies also helped formulate the latter [1].

First, the researchers subjected burnt rock to compressive testing, identified the parameters of basic slurries and the properties of rock-based plugging mixtures by applying them to dumped rock (debris) from the Yubileynaya and Yuzhnaya mines.

Debris were compression-tested by Litvinov instruments. Such instruments can supply 
water to, and remove it from, a specimen; they expose each specimen centrally to a constant pressure at any step. The instrument was used to test debris samples, both naturally humid and completely water-saturated. Each specimen was $3.5 \mathrm{~cm}$ in height and $40 \mathrm{~cm} 2$ in area. Initial pressure specimens were subjected to was $2.5 \mathrm{kPa}$ before thickening onset. The adopted thickening onset corresponded to the strain $\varepsilon>0.005$.

Specimens were loaded stepwise with 0.1-МРa increments. ИЧ-10 dial gages were used to measure changes in specimen height. Such changes were recorded in $0.25 ; 0.5 ; 1 ; 2 ; 10$; and 15 minutes, and so on, until strain stabilized. Strain was deemed stabilized if at any observation step, the deformation change $h_{-} i<0,001 \mathrm{~mm}$ was observed.

\section{Results and Discussion}

Study results are presented as the specimen strain as a function of applied pressure at natural humidity and when water-saturated, see Figures 2 and 3.

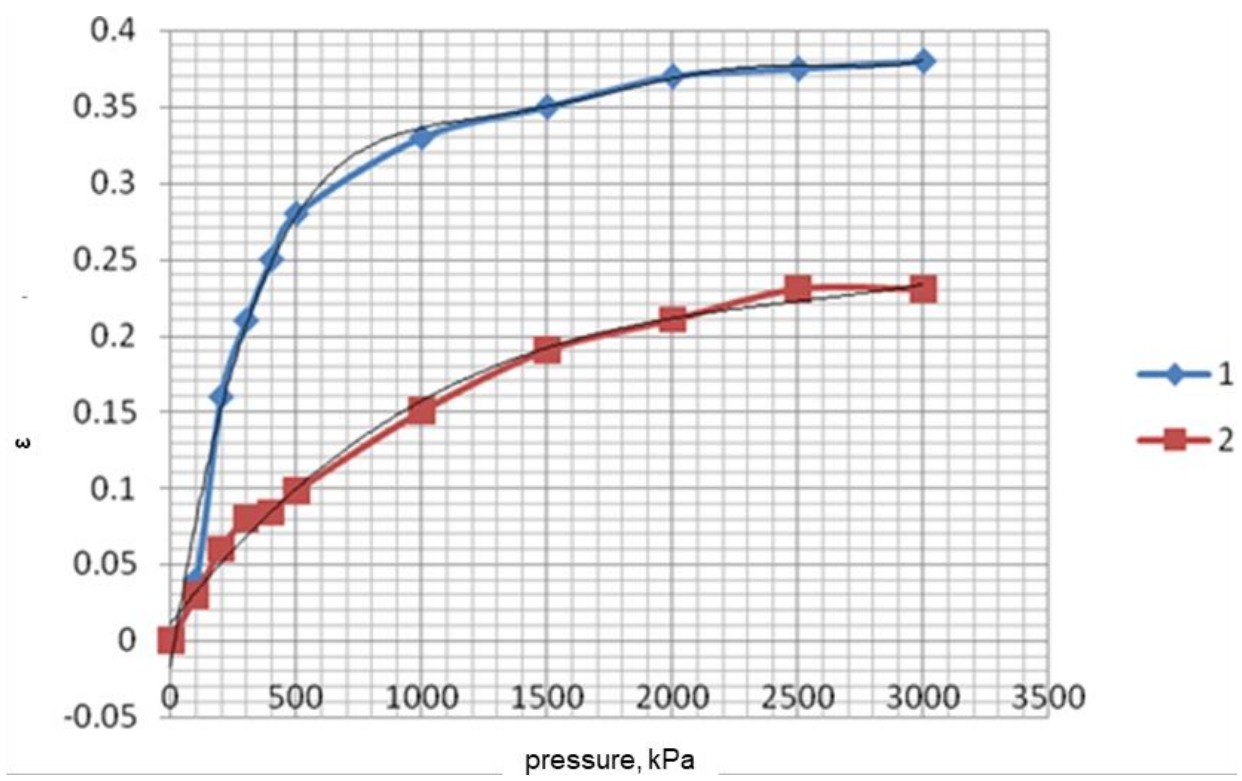

Fig. 2. Debris strain (Yuzhnaya mine): 1 for water-saturated specimens; 2 for naturally humid debris.

Studies identified a $25 \%$ to $30 \%$ rock shrinkage; the humidity was found to significantly affect the manifestation and magnitude of pressure-caused strain. Backfill massif is hydrated while being shaped, which increases the shrinkage rate by up to $25-45 \%$.

Given how extraordinarily dangerous supra-opening surface cavities are, environmentally safe, shrinkage-free high-quality cavity filling is a must. Structured plastic mass is made of fine-grained matter that may be supplemented with coarse-grained fillers. Portland cement, whether with or without active mineral additives, can be used for binding the hardening backfill blends. 


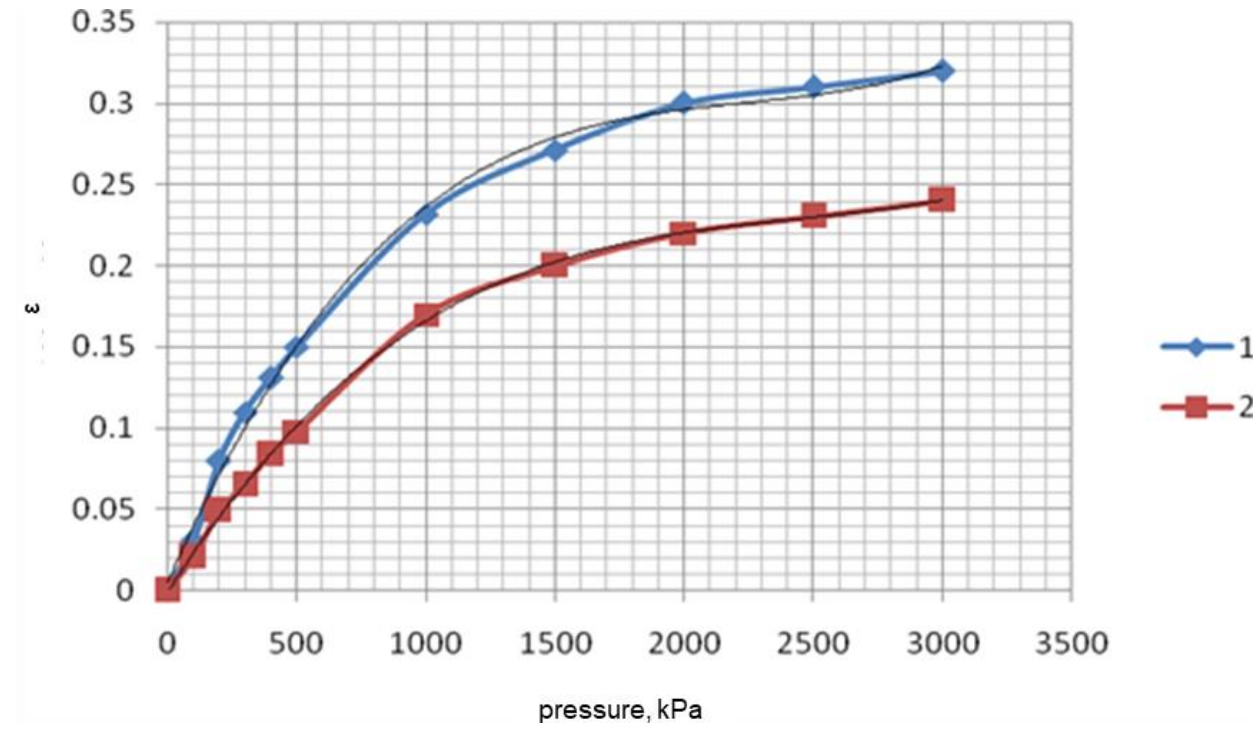

Fig. 3. Debris strain (Yubileynaya mine): 1 for water-saturated specimens; 2 for naturally humid debris.

However, such blends do not fully meet the requirements to the materials and methods of forming the backfill massif in cavity zones. Various mining conditions of supra-opening cavitation may require in-site adjustments in the properties of plugging slurries. That is why when analyzing the formulation of backfill slurries, it is necessary to study the strength of mixtures as affected by binder content.

For plugging slurries, the basic parameters are density, strength, and rheology. Since lowcement clay-rock slurries do not for a stiff frame, let us use plastic strength as the strength indicator. The strength of a plugging slurry can be adjusted by altering the amount of added cement, which is why a cement-free clay-rock slurry is considered baseline. Table 1 presents examples of debris-based baseline slurries.

Table 1. Baseline slurry parameters.

\begin{tabular}{|c|c|c|c|c|}
\hline Mine debris & $\begin{array}{c}\text { Clay mud } \\
\text { density, } \\
\mathrm{kg} / \mathrm{m}^{3}\end{array}$ & $\begin{array}{c}\text { Allowable } \\
\text { percentage of rock } \\
\text { in the clay mud }\end{array}$ & $\begin{array}{c}\text { Ultimate density } \\
\text { of the baseline } \\
\text { slurry, } \mathrm{kg} / \mathrm{m}^{3}\end{array}$ & $\begin{array}{c}\text { Time to fill in a } \\
\text { portion, min }\end{array}$ \\
\hline Yuzhnaya & 1,006 & 0.365 & 1,450 & 15 \\
\hline Yubileynaya & 1,005 & 0.368 & 1,450 & 15 \\
\hline
\end{tabular}

Find the plastic strength of slurries by the Rebinder method; to that end, measure the cone depth at a specified angle and a specified applied pressure. To attain a sufficient accuracy of measurement, dip the cone three to five times in different specimen spots. Table 2 presents the composition and properties of the tested plugging slurries. 
Table 2. Composition and properties of plugging slurry formulations.

\begin{tabular}{|c|c|c|}
\hline \multirow{2}{*}{ Parameter } & \multicolumn{2}{|c|}{ Value } \\
\cline { 2 - 3 } & 1 & 2 \\
\hline Amount of rock with $<5$-mm particles, $\mathrm{kg} / \mathrm{m}^{3}$ & 860 & 860 \\
\hline Bentonite powder, $\mathrm{kg} / \mathrm{m}^{3}$ & 8 & 8 \\
\hline Water $\mathrm{kg} / \mathrm{m}^{3}$ & 582 & 582 \\
\hline Density of the baseline slurry, $\mathrm{kg} / \mathrm{m}^{3}$ & 1,450 & 1,450 \\
\hline M400 cement, $\mathrm{kg} / \mathrm{m}^{3}$ & 40 & 60 \\
\hline Slurry density, $\mathrm{kg} / \mathrm{m}^{3}$ & 1,472 & 1,478 \\
\hline Plastic strength, $\mathrm{kPa}$ & & \\
\hline - in 1 minute & 0.32 & 0.32 \\
\hline - after 10 days & 280.9 & 398.8 \\
\hline Dynamic shear stress, Pa & 30.5 & 32.6 \\
\hline Shrinkage, $\%$ & 0 & 0 \\
\hline Spreadability, cm & 9 to 11 & 9 to 10 \\
\hline Angle of repose, degrees & 15 & 15 \\
\hline
\end{tabular}

Data shows that plugging slurries reach up to $90 \%$ of their strength in 9 to 11 days.

The entire set of works to close a supra-opening surface cavity can be divided into two steps: preparation and actual closure.

During the preparations, they:

- restrict movement in the cavity zone;

- prepare the site, install the equipment, and identify the car routes;

- extract the debris and prepare the materials in necessary amounts.

Closure itself includes the following works:

- forming the backfill massif in the cavity zone;

- prevention of backfill-massif deformation;

- prevention of backfill-material removal;

- plugging the fractured rock around the cavity, if necessary;

- cavity closure quality control.

The technology of supra-opening surface cavity closure can be shown as a sequence of series-connected logical blocks (Figure 4), completing which enables thorough in-situ monitoring and adjustment of backfill material properties.

The selected cavity closure procedure must be case-specific, technically and economically sound, and adjusted to the production, mining, environmental, and social factors, especially the preserved mine infrastructure. Based on the generalized procedure of cavity closure under various supra-opening surface cavity closure conditions, the baseline procedures have been identified, see Figures 5 and 6 . The applicability of these procedures depends on the strain requirements to the backfill massif, on the distance to materials, on the preservation of mine communications, on the location of the emergency site, and on how critical the final result will be.

Procedure 1 in Figure 5 is the simplest procedure for closing surface cavities by backfilling with unscreened rock, Blocks A and B. 


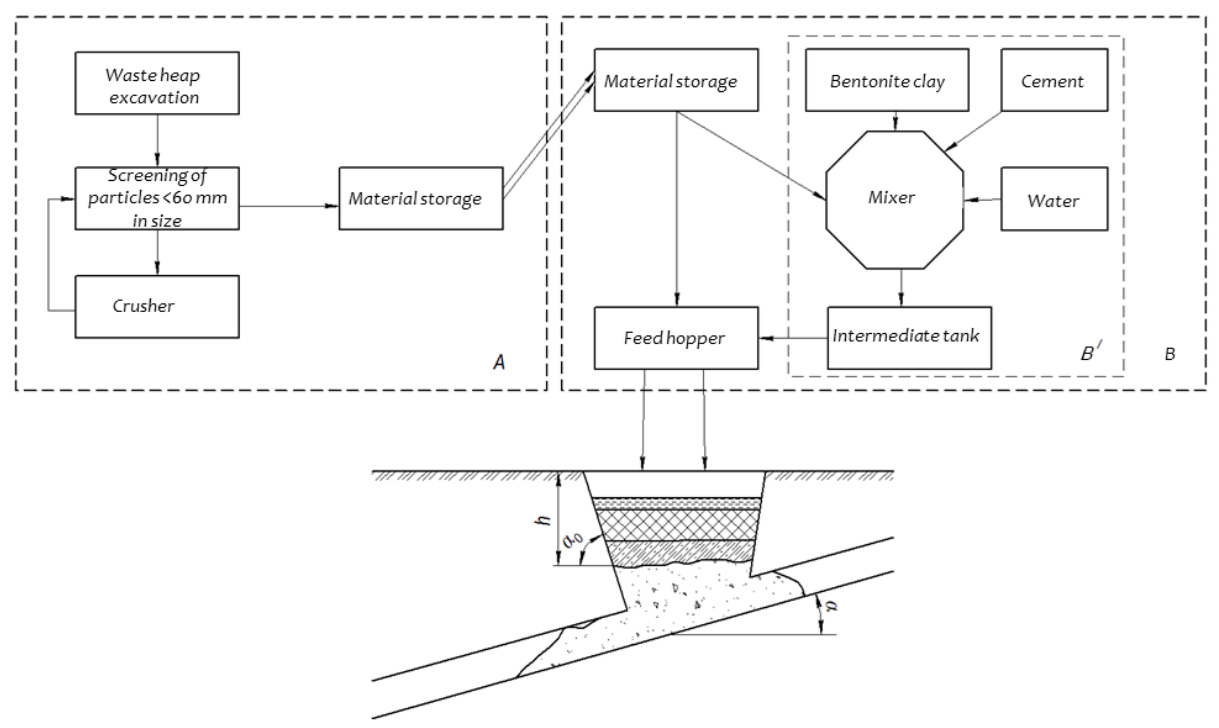

Fig. 4. Generalized surface cavity closure procedure: $A$ is the backfill material framing and associated preparations; B is the backfill massif formation by backfilling; B' is the plugging slurry preparation.

Burnt rock is developed by bulldozers and excavators to fill the surface cavities. To produce a backfill massif of required parameters, rock is screened by a vibrating screen to the necessary particle size. Additional crushing may apply. Burnt rock is collected at the emergency site. The backfill massif is formed by backfilling the cavity with burnt rock without extra thickening. Waterproofing is done by making a clayey seal layer and installing additional drainers.

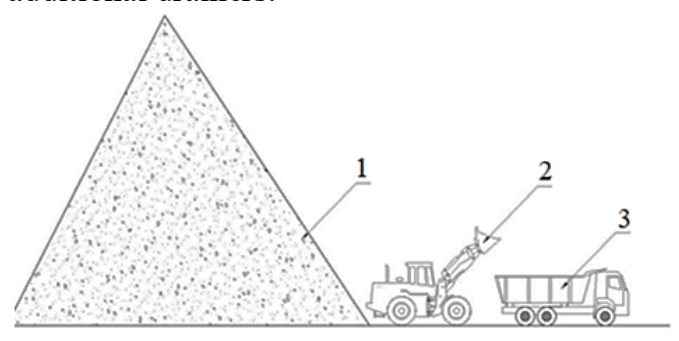

a)

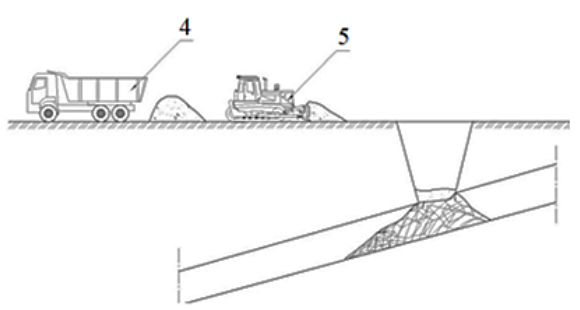

b)

Fig. 5. Procedure of surface cavity closure by backfilling with unscreened rock: (a) preparation of debris; (b) works; 1 is debris; 2 is a loader; 3 and 4 is a dump truck; 4 is a bulldozer.

This procedure is applicable in low-water and water-free massifs where non-soaking shrinkage-free backfill material is used.

In case the massif is exposed to periodic flooding, where mines are closed by "wet" abandonment using debris, the application of Procedure 1 is limited by the strain of the used material.

Procedure 2 in Figure $6(\mathrm{~A}+\mathrm{B}+\mathrm{B}$ ' set of actions) is a more advanced variation of Procedure 1. Cavities are closed with debris of particle size $\delta \leq 60 \mathrm{~mm}$ for a highly dense rock skeleton. 


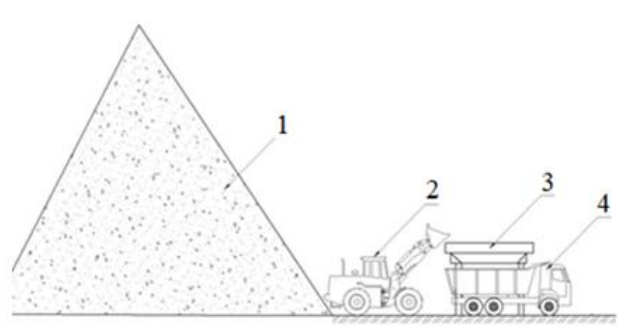

a)

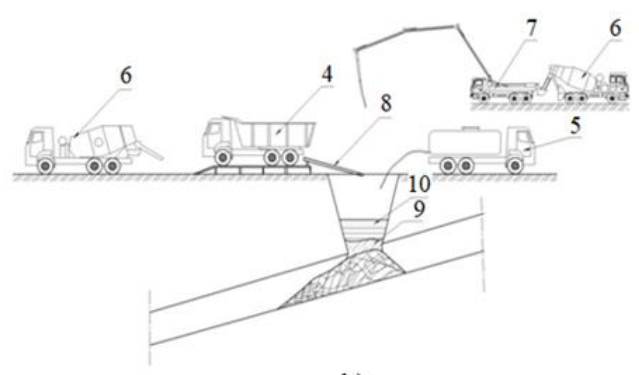

b)

Fig. 6. Procedure of surface cavity closure by layered plugging: (a) preparation of debris; (b) works; 1 is debris; 2 is a loader; 3 is a vibrating screen; 4 is a dump truck; 5 is a water tank; 6 is a concrete mixer; 7 is a truck-mounted pump; 8 is a rack with a distributing chute.

For more uniform and controllable straining of the backfill massif, the cavity is filled layer by layer. To prevent small-particle $(5 \mathrm{~mm})$ rock from being removed from the backfill, the massif is divided by plugging layers into dasses.

For Eastern Donbass, Procedure 2 is a more efficient solution for cavities exceeding 15 $\mathrm{m} 3$ in volume and $1.2 \mathrm{~m}$ in depth.

\section{Conclusions}

1. Production of plugging slurries of different strength from the same baseline slurry minimizes the cost of backfill massif property adjustments. Depending on its properties, slurry can be either pumped through a pipe or fed to the cavity through an inclined chute without extra pressure.

2. Industrial testing of Procedure 2 using the developed plugging slurry formulation proved it efficient and reliable for closing cavities above inclined openings of closed coal mines.

The reported study was funded by FSBEI HE DSTU under the University Grants for Scopus and Web of Science publications.

\section{References}

1. P. Dolzhikov, A. Prokopov, M. Prokopova, N. Hamidullina. MATEC Web of Conferences. 196, 03008. https://doi.org/10.1051/matecconf/201819603008.

2. P. Dolzhikov, A. Prokopov, V. Akopyan. Advances in Intelligent Systems and Computing, 692, (2017). DOI: https://doi.org/10.1007/978-3-319-70987-1_69.

3. N. Kachurin, V. Komaschenko, V. Golik, V. Morkun. E3S Web of Conferences, 60 (2018). DOI: https://doi.org/10.1051/e3sconf/20186000031.

4. N. Kachurin, S. Vorobev, P.Vasilev. XVIII International Coal Preparation Congress, 2016, 609-614 (2016). DOI: 10.1007/978-3-319-40943-6_93.

5. M. Molev, V. Armeiskov, M. Golodov. Mining Informational and Analytical Bulletin, 3, 63-73 (2019). DOI: 10.25018/0236-1493-2019-03-0-63-73.

6. M. Molev, A. Kovaleva, I. Zanina, N. Stuzhenko, Yu. Chertov Modeling of Environmental Safety of Industrially Developed Regions of Russia. (Atlantis Press, 2019) DOI: https://doi.org/10.2991/isees-19.2019.17. 
7. A. Mokhov. Doklady Earth Sciences. 473, 390-393. (2017). DOI: 10.1134/S1028334X17040043

8. A. Mokhov. Doklady Earth Sciences. 452, $904-906$ (2013). DOI: 10.1134\%2FS1028334X13080035

9. B. Meskhi, M. Pleshko, Y. Buligin, L. Alexeenko, M. Molev. IOP Conference Series: Earth and Environmental Science. 90(1), 012217 (2017). DOI: http://dx.doi.org/10.1088/1755-1315/90/1/012217.

10. M. Pleshko, I. Voinov, A. Revyakin. MATEC Web of Conferences. 106, 05004 (2017). DOI: $10.1051 /$ matecconf/201710605004.

11. A. Prokopov, M. Prokopova, N. Hamidullina. IOP Conference Series: Earth and Environmental Science, 272(2) (2019). DOI: 10.1088/1755-1315/272/2/022118.

12. A. Baryakh, S. Devyatkov. Gornyy zhurnal. 6, 17-21 (2018). DOI: 10.17580/gzh.2018.06.03.

13. G. Chen, T. Li, Y. He, L. Wei, Z. Zhou. Tumu jianzhu yu huanjing gongcheng, 35(1), 52-56 (2013). DOI: 10.3969/j.issn.1674-4764.2013.01.009.

14. A. Prokopov, V. Zhur, A. Medvedev. MATEC Web of Conferences, 196, 03009 (2018). DOI: https://doi.org/10.1051/matecconf/201819603009.

15. A. Prokopov, V. Matua, V. Akopyan. Procedia Engineering, 150 (2016), 2255-2260. DOI: https://doi.org/10.1016/j.proeng.2016.07.280

16. A.K. Baiburin, M.M. Rybakov, N.I. Vatin. Magazine of Civil Engineering, 85(1), 3-14 (2019). DOI:10.18720/MCE.85.1.

17. Y. Barabanshchikov, I. Fedorenko, S. Kostyrya, K. Usanova. Advances in Intelligent Systems and Computing 983, 858-866 (2019). DOI:10.1007/978-3-030-19868-8_84. 